\title{
Seasonal Characteristics of Mesoscale Coupling between the Sea Surface Temperature and Wind Speed in the South China Sea
}

\author{
SHUANGWEN SUN AND YUE FANG \\ Center for Ocean and Climate Research, First Institute of Oceanography, Ministry of Natural Resources, and Laboratory for Regional \\ Oceanography and Numerical Modeling, Pilot National Laboratory for Marine Science and Technology, Qingdao, China \\ YONGCAN ZU, BAOCHAO LIU, AND TANA \\ Center for Ocean and Climate Research, First Institute of Oceanography, Ministry of Natural Resources, Qingdao, China
}

\author{
AZIZAN ABU SAMAH
}

Institute of Ocean and Earth Sciences, University of Malaya, Kuala Lumpur, Malaysia

(Manuscript received 30 May 2019, in final form 4 October 2019)

\begin{abstract}
The seasonal characteristics of the mesoscale coupling between sea surface temperature (SST) and wind speed in the South China Sea (SCS) are investigated using satellite observations. The correlation between mesoscale SST and wind speed is highest in winter. The region of high correlation is located in the central SCS in the early stage of the winter monsoon. It then gradually shifts northward in the following months and is located in the northern SCS in the late stage of the winter monsoon. In summer, the region of high correlation is located to the east of the Vietnam coast. Two controlling factors are crucial in mesoscale SST-wind speed coupling: the mesoscale SST gradient and the wind speed steadiness. The mesoscale SST gradient is fundamental in mesoscale coupling, but a steady wind speed also plays an important role. The development of significant coupling depends on the relative contribution of these two factors. For regions where the mesoscale SST gradient is relatively weak, a very steady wind field is required for detectable mesoscale coupling to occur, whereas in regions where the wind speed is less steady, a stronger mesoscale SST gradient must exist for coupling to develop. Variations in wind speed steadiness can well explain the inconsistency between the spatial patterns of the mesoscale SST gradient and the intensity of coupling. The wind speed steadiness is a good factor with which to evaluate the constraining effect of the background wind field variability on the development of mesoscale coupling in the SCS.
\end{abstract}

\section{Introduction}

High-resolution satellite observations have shown that sea surface temperature (SST) and wind speed are positively correlated on oceanic mesoscales in both the tropics and extratropics. (Chelton et al. 2001; Xie 2004; Small et al. 2008). Such a positive SST-wind relationship is mainly due to the SST's modification of stability and vertical mixing in the atmospheric boundary layer. Cold water stabilizes the atmosphere boundary layer and thus decouples the winds at the sea surface from those at a greater height, whereas heating over warm water deepens and destabilizes the atmospheric boundary layer, decreasing the wind vertical shear (Hayes et al.

\footnotetext{
Corresponding author: Yue Fang, yfang@fio.org.cn
}

1989; Wallace et al. 1989; Hashizume et al. 2001; Xie et al. 2001). Other key mechanisms have also been proposed as underlying this positive relationship, including secondary circulation in the boundary layer driven by pressure gradients across SST fronts (Lindzen and Nigam 1987; Wai and Stage 1989) and wind stress change associated with fronts and eddy currents, which can impact the relative motion of the air and ocean (Cornillon and Park 2001; Kelly et al. 2001). The positive correlation between SST and wind speed is most significant in regions where there are prominent oceanic fronts, such as the Kuroshio and its extension (Nonaka and Xie 2003), the Southern Ocean (O'Neill et al. 2003; Perlin et al. 2014), the eastern tropical Pacific (Chelton et al. 2001), and the Gulf Stream rings (Park and Cornillon 2002). 
Strong air-sea coupling at oceanic mesoscales exerts remarkable influences on many atmospheric and oceanic processes. On one hand, it can be vital in modifying near-surface winds, cloud properties, water vapor content, and rain rate over regions where there are prominent oceanic fronts (Chelton et al. 2004; Bryan et al. 2010; Frenger et al. 2013; Ma et al. 2015). Plus, in addition to local processes, there is evidence that SST frontal effects can extend beyond the boundary layer into the free troposphere and further influence the large-scale circulation of the atmosphere (Chelton and Xie 2010). On the other hand, atmospheric perturbations induced by the SST may feed back to the ocean through upperocean wind mixing and wind-driven upwelling, significantly altering the oceanic circulation and the SST itself (Chelton and Xie 2010). Changes in wind speed and cloud fraction also affect the SST by inducing variations in heat flux at the sea surface (Frenger et al. 2013). The atmospheric variations induced by SST play an important role in modulating the propagation, life cycle, intensity, and other transient features of eddies (White and Annis 2003; Small et al. 2008; Jin et al. 2009; Seo et al. 2016). Mesoscale SST-wind coupling is not only important to local oceanic processes but is also fundamental to the dynamics of large-scale ocean currents (X. Ma et al. 2016).

Early studies of mesoscale SST-wind coupling mainly focused on the major frontal zones and high-eddyactivity regions of open oceans. Recent studies have shown that coupling is also significant in some marginal seas where the SST gradient is strong (e.g., coastal upwelling regions) and the coupling in these regions is strongly modulated by variations in the wind directional steadiness (WDS) (Chelton et al. 2007; Castelao 2012; Desbiolles et al. 2014). The intensity of coupling is usually weaker in regions with a higher variability in wind direction, and vice versa (Chelton et al. 2007; Castelao 2012; Desbiolles et al. 2014). In contrast with coupling in open oceans, coupling in marginal seas is more spatially and temporally variable due to the complex oceanic and atmospheric background conditions (Vecchi et al. 2004; Chelton et al. 2007; Desbiolles et al. 2014; Castelao 2012; Oerder et al. 2016). The wind direction in marginal seas usually changes with the seasons, and thus the upwelling and SST front induced by offshore winds, which are crucial in the development of mesoscale coupling, only occur in certain months of the year. The strong seasonal variation in the intensity or stability of winds may influence mesoscale coupling. Moreover, the background atmospheric boundary layer stability also plays a significant role in the seasonal variation of atmospheric responses to oceanic eddies (Chelton et al. 2007; J. Ma et al. 2016). The seasonal variations in SST in marginal seas are usually more remarkable than those in the open oceans, which further increases the complexity of the background conditions of mesoscale coupling.

Several aspects of mesoscale coupling in marginal seas are not yet understood. Previous studies have suggested that a strong SST gradient and strong and steady winds favor mesoscale coupling, but the coupling is not necessarily significant in the regions where those conditions coexist. However, significant coupling can sometimes be detected over weak SST gradients in certain regions. These findings suggest that the development of mesoscale coupling depends on multiple factors, and that these factors may also interact with each other. The controlling factors for coupling may vary with regions. Most existing studies on mesoscale coupling in marginal seas focused on regions in which coastal upwelling is strong (Vecchi et al. 2004; Chelton et al. 2007; Jin et al. 2009; Castelao 2012; Desbiolles et al. 2014; Oerder et al. 2016), but whether significant mesoscale coupling exists in other types of marginal seas and, if so, the nature of the underlying mechanisms, is unknown.

The South China Sea (SCS) is a large semiclosed marginal sea dominated by the East Asian monsoon system. Driven by southwesterly winds in summer and northeasterly winds in winter, the oceanic and atmospheric background conditions show remarkable seasonal differences. As a result of the complexity of the ocean-atmosphere system and the unique orographic effects in the SCS, mesoscale coupling in this region is very complex (Xie et al. 2007; Chow and Liu 2012; Wang et al. 2012; Sun et al. 2016). The purpose of this paper is to explore the seasonal characteristics of mesoscale coupling between SST and wind speed in the SCS and to investigate the mechanisms and key factors related to these characteristics.

The rest of the paper is organized as follows: section 2 describes the datasets. Section 3 presents the seasonal characteristics of mesoscale SST-wind speed coupling. Sections 4 and 5 investigate the roles of the SST gradient and wind field in mesoscale coupling, respectively. Conclusions are summarized in section 6 .

\section{Data}

Two sets of weekly data from July 1999 to November 2009 are used in this study. The SST data are from the Tropical Rainfall Measuring Mission satellite's Microwave Imager (TMI) product produced by the Remote Sensing Systems Co. (Wentz et al. 2000), and the wind fields at $10 \mathrm{~m}$ above the sea surface are from QuikSCAT (version 4), also produced by Remote Sensing Systems (Ricciardulli and Wentz 2011). The SST anomalies 
(SSTAs) and wind speed anomalies (WSAs) are calculated by removing the annual cycles (defined as the annual mean plus the first three harmonics with periods of $365.25,182.625$, and 121.75 days). To remove the variability induced by synoptic weather processes, which is not related to SST-wind coupling, a five-week low-pass filter is applied to the SSTAs and WSAs. In addition to this temporal filter, a loess filter (Cleveland and Devlin 1988 ) with half-power filter cutoff wavelengths of $2^{\circ}$ latitude by $2^{\circ}$ longitude is also applied to the SSTAs and WSAs, to remove the large-scale spatial variations related to the background fields.

\section{Seasonal variation of SST-wind speed coupling}

Figure 1 shows the seasonal variation of the intensity of coupling between the SST and wind speed in the SCS. The intensity of coupling is represented by the correlation coefficient between the SSTAs and the WSAs, as adopted by previous studies (e.g., Chelton et al. 2007; Small et al. 2008). The strong seasonality of the intensity of coupling is reflected well by the spatial variation of regions with strong coupling (intensity of coupling $>$ 0.5 ), where the intensity of coupling is comparable to that of the major frontal zones in the open ocean (Small et al. 2008).

In winter (from November to the following March), the SCS is dominated by strong northeasterly winter monsoon winds. In the early stage of the winter monsoon (November-December), the region of strong coupling is mainly located in the central basin of the SCS between $11^{\circ}$ and $20^{\circ} \mathrm{N}$. As the season proceeds, the region of strong coupling gradually shifts to the north, and by February it is mainly located to the north of $15^{\circ} \mathrm{N}$. The coupling to the south of $15^{\circ} \mathrm{N}$ weakens further in March and the region of strong coupling is confined to the north of $15^{\circ} \mathrm{N}$ and a narrow band along the western coast of the SCS. Interestingly, although the background wind speed and wind direction do not vary much during the winter months, the location of the strong-coupling region changes greatly in the different stages of the winter monsoon.

Southwesterly winds prevail during the summer months (June-August). The region of strong coupling is located off the east coast of Vietnam and has a stable spatial distribution. However, the intensity of coupling is not the same in these three months and is strongest in July. The intensity of coupling in summer is generally weaker than that in the winter months.

Spring (April-May) is a transitional period between the winter and summer monsoons in which the winter coupling pattern gradually translates into the summer coupling pattern. Fall (September-October) is also a transitional season, and the intensity of coupling in this season is weaker than in the rest of the year, with only isolated pockets of high correlation between the SSTAs and WSAs.

This analysis shows that the intensity and spatial distribution of mesoscale coupling between the SSTAs and WSAs in the SCS possess remarkable seasonal variation. These unique characteristics are very different from those of the mesoscale coupling in upwelling regions reported in previous studies. Therefore, we further explore the mechanisms underlying this mesoscale coupling in the SCS in different seasons.

\section{Influence of SST gradient on coupling}

The SST gradient associated with mesoscale oceanic processes has been proven to be necessary for the development of mesoscale coupling between SST and surface winds. Therefore, we first explore the role of SST in the seasonal variation of mesoscale coupling by investigating the relationship between the mesoscale SST gradient (MTG), calculated from the filtered SSTAs described in section 2, and the intensity of coupling.

Figure 2 shows the MTG and the intensity of coupling in four representative months (March, July, September, and December). In the late stage of the winter monsoon (represented by March), except for the northern coastal regions, the spatial distribution of regions with a high intensity of coupling (correlation coefficient $\geq 0.5$ ) coincides well with that of a strong MTG $\left[\geq 0.35^{\circ} \mathrm{C}\right.$ $(100 \mathrm{~km})^{-1}$ ] (Fig. 2a). This suggests that the strong mesoscale coupling between the SST and surface winds in late winter is mainly a result of the MTG, consistent with previous findings on mesoscale air-sea interactions (e.g., Xie 2004; Chelton and Xie 2010).

During the summer monsoon (represented by July), the area of strong coupling is much smaller than that in March, although the area with a strong MTG is much larger than that in March and covers most of the SCS (Fig. 2b). The region of strong coupling mainly appears in the western SCS, just off the coast of Vietnam, where the MTG is strongest. Therefore, in the summer months, mesoscale coupling can only develop in certain regions where the MTG is strong.

In the monsoon transition period (represented by September), almost the entire SCS is characterized by a strong MTG (Fig. 2c). However, strong coupling is rarely seen in this period, suggesting that a strong MTG is insufficient as a condition for mesoscale coupling to develop in this transition period, and that other factors need to be taken into account.

In comparison with the three seasons mentioned above, the spatial distributions of strong mesoscale 
(a) Jan

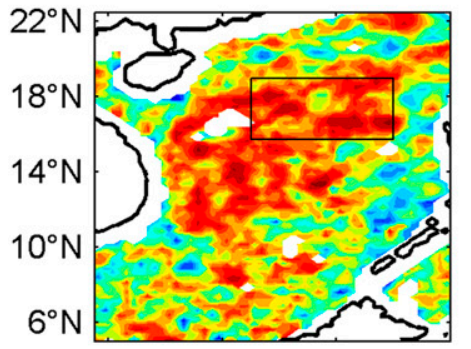

$108^{\circ} \mathrm{E} 112^{\circ} \mathrm{E} 116^{\circ} \mathrm{E} 120^{\circ} \mathrm{E}$ (b) Feb

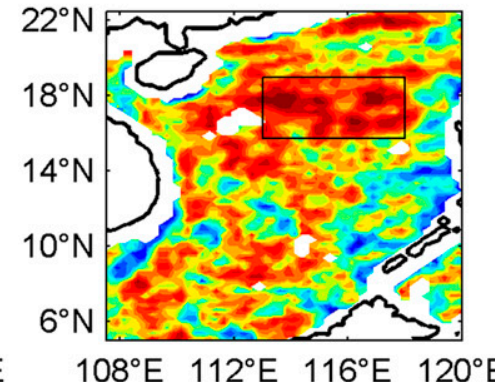

(e) May

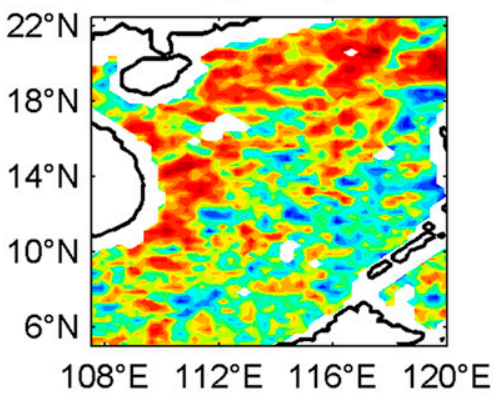

(h) Aug

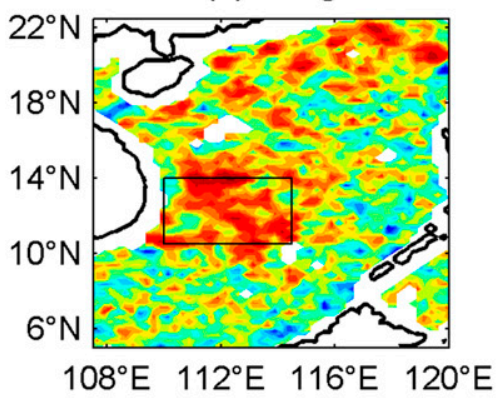

(k) Nov

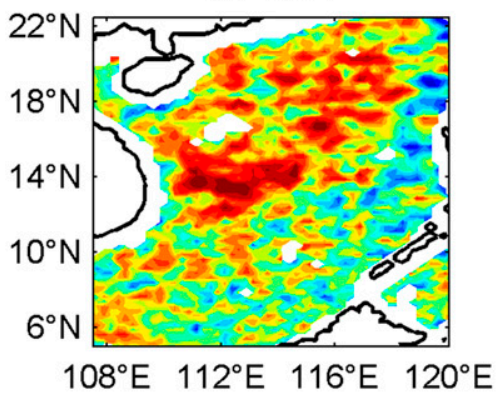

(c) Mar

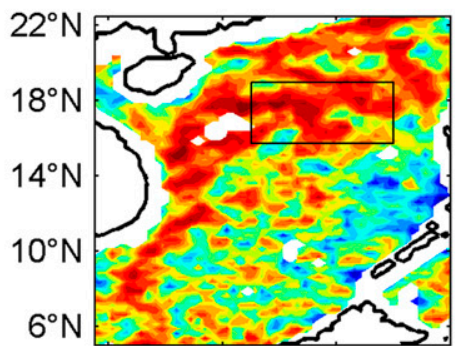

$108^{\circ} \mathrm{E} \quad 112^{\circ} \mathrm{E} \quad 116^{\circ} \mathrm{E} \quad 120^{\circ} \mathrm{E}$

(f) Jun

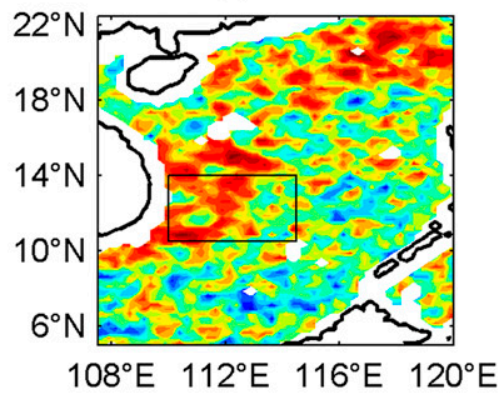

(i) Sep

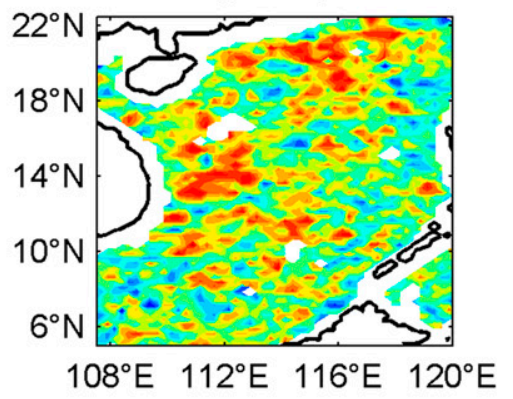

(I) $\mathrm{Dec}$

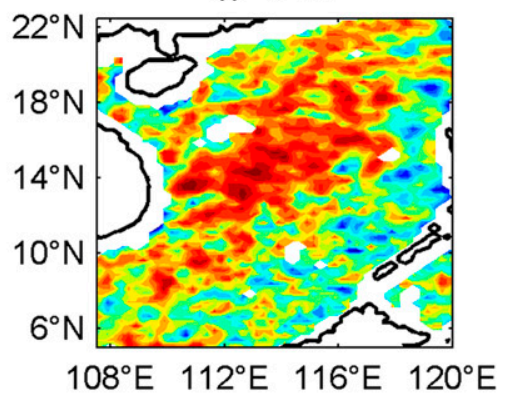

$\begin{array}{lllllllll}-0.8 & -0.6 & -0.4 & -0.2 & 0 & 0.2 & 0.4 & 0.6 & 0.8\end{array}$

FIG. 1. Seasonal variation in the intensity of mesoscale coupling (represented by the correlation coefficient between the SSTAs and WSAs) in the SCS. The black-outlined boxes represent the regions over which the statistics in Fig. 7 are computed. 
(a) Mar

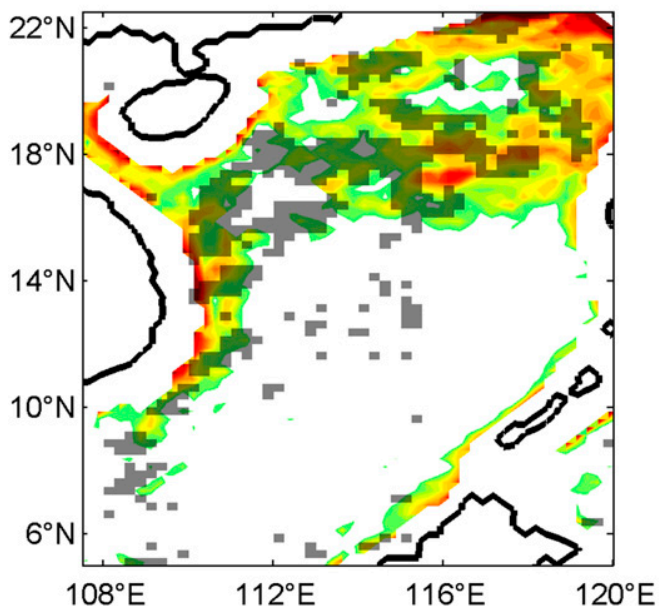

(c) Sep

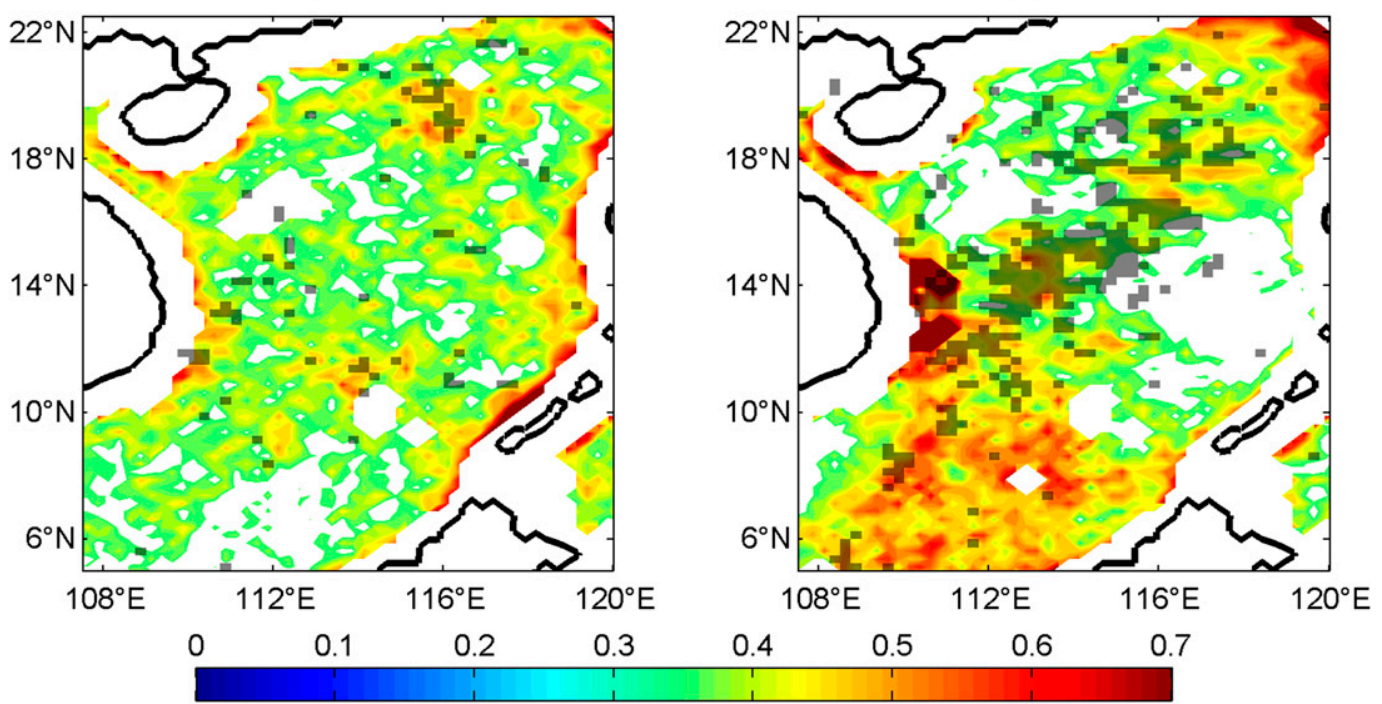

FIG. 2. Seasonal variation in the mesoscale SST gradient [shading; only values $\geq 0.35^{\circ} \mathrm{C}(100 \mathrm{~km})^{-1}$ are plotted] and the intensity of coupling (represented by the correlation coefficient between the SSTAs and WSAs; values $\geq$ 0.5 are shaded gray) in (a) March, (b) July, (c) September, and (d) December. (b) Jul

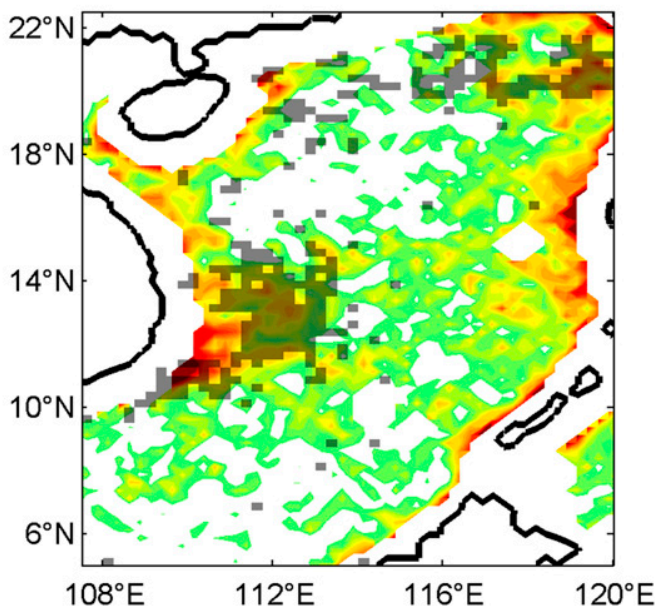

(d) Dec coupling and a strong MTG are more complex in early stages of the winter monsoon (represented by December; Fig. 2d). The MTG is strongest in this season, particularly in the southern SCS, although the regions of strong coupling are mainly located in the northern SCS and no significant coupling is found south of $10^{\circ} \mathrm{N}$. This is unusual considering that the MTG in the southern SCS is much stronger than that in the northern SCS, implying that the mechanisms underlying the mesoscale coupling in the northern and southern SCS may be different in this season.
Although the mesoscale coupling in Fig. 2 shows remarkable seasonal differences in spatial distribution and strength, a common feature of coupling in different seasons is fairly clear: mesoscale coupling between SST and surface winds can only develop in regions where the MTG is strong. This suggests that the MTG is fundamental to the development of mesoscale coupling in the SCS.

It is clear that the mesoscale SST gradient in the SCS is characterized by strong seasonality. Accordingly, we use March and July as representative of the winter and summer months to examine this seasonality. 
(a) Mar

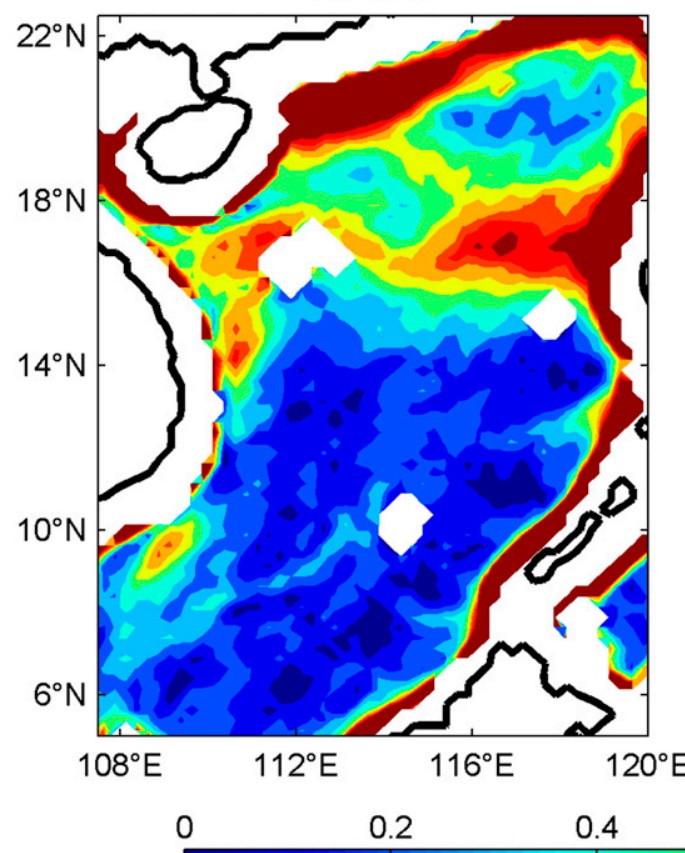

(b) Jul

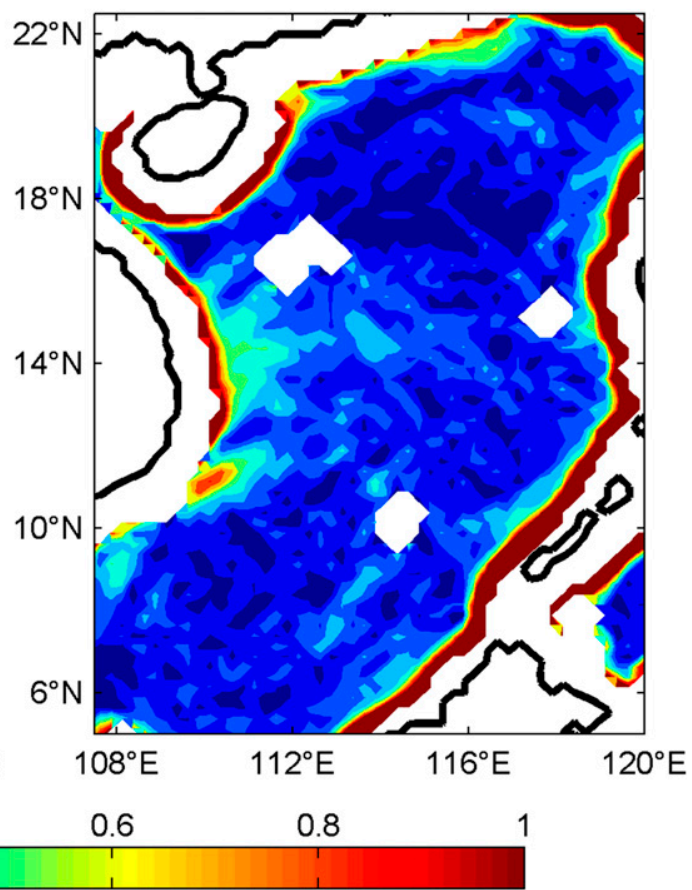

FIG. 3. Climatological SST gradient $\left[{ }^{\circ} \mathrm{C}(100 \mathrm{~km})^{-1}\right]$ in (a) March and (b) July.

In winter, the MTG is tightly linked to the climatological SST field or the large-scale distribution of SST. Figure 3a shows that the climatological SST front appears in the northern SCS and stretches westward from the east coast of the SCS at about $17^{\circ} \mathrm{N}$. In addition to this major front, a strong climatological SST gradient also exists in the coastal regions of the SCS. These regions are consistent with the regions with a strong MTG (Fig. 2a). This is because, in the regions where the climatological SST gradient is strong, anomalous horizontal heat advection induced by mesoscale oceanic processes, such as eddies, is also expected to be strong and will lead to strong mesoscale perturbations of the SST, thus generating a strong MTG.

In summer, the SCS is characterized by a uniformly distributed high SST, so the climatological SST gradient is rather weak (Fig. 3b). However, the MTG is still very strong in most parts of the SCS (Fig. 2b). As we know, the mixed layer is much shallower in summer than in winter (Qu 2001), and therefore the thermocline is also shallower. Thus, any temperature perturbation associated with anomalous vertical heat advection induced by mesoscale oceanic processes can easily cause an increase in the MTG. Another notable feature in summer is the strong MTG in the western SCS, which is attributable to the special atmospheric forcing in this region. The SCS is controlled by southwest monsoon winds in summer. As the southwest monsoon winds impinge on the mountain range along the east coast of the Indochina Peninsula, orographic blocking accelerates the winds at the southern tip of the Annam Cordillera, leading to a strong offshore wind jet. This wind jet initiates coastal upwelling and produces a cold filament in the SST and eddies (Wang et al. 2003; Xie et al. 2003). These mesoscale oceanic processes could induce significant SSTAs, resulting in a strong SST gradient in this region.

\section{Influence of winds on coupling}

\section{a. Effects of wind directional steadiness and wind speed}

Since SST-wind coupling mainly arises from the response of the atmospheric boundary layer to mesoscale SST changes, the condition of the winds in the atmospheric boundary layer is expected to play an important role in the development of SST-wind coupling. If the wind direction is highly unstable, then the wind variations induced by the SST could easily be masked by the energetic variability of the wind field itself. If the wind speed is too low, then the response of the wind to the SST would be too weak to be detected. Stable and strong winds are therefore necessary for detectable SST-wind coupling. Previous studies have shown that both the 
(a) Mar

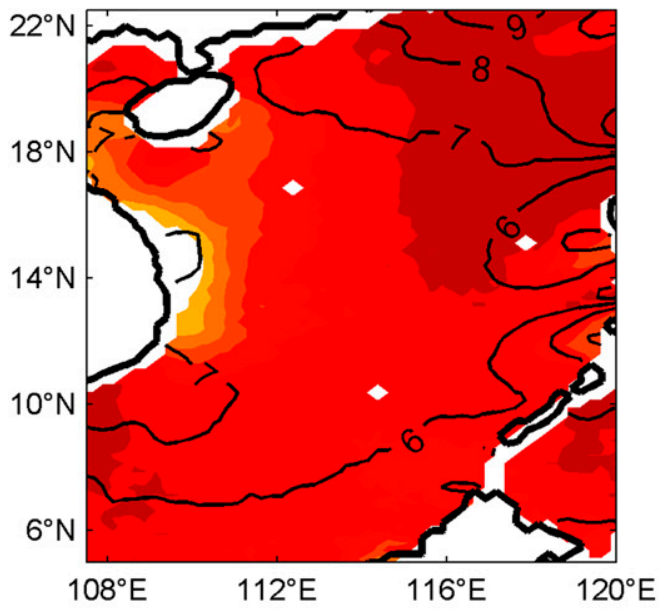

(c) Sep

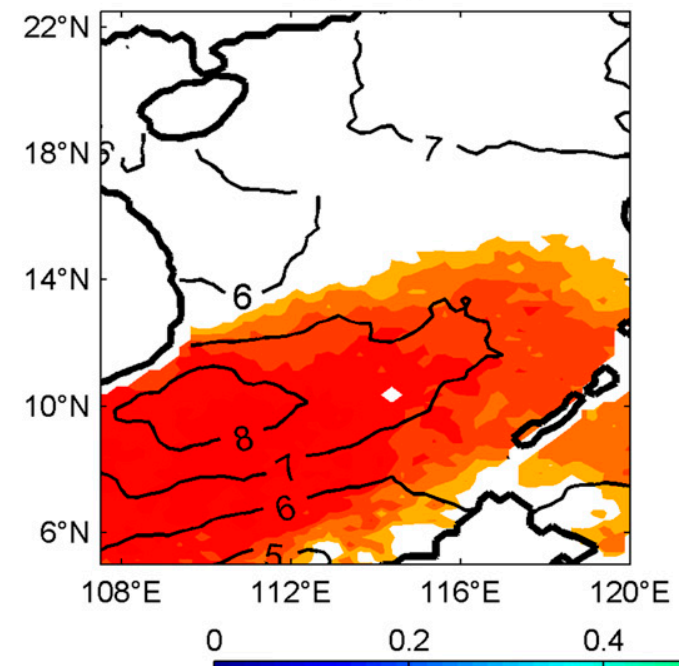

(b) Jul

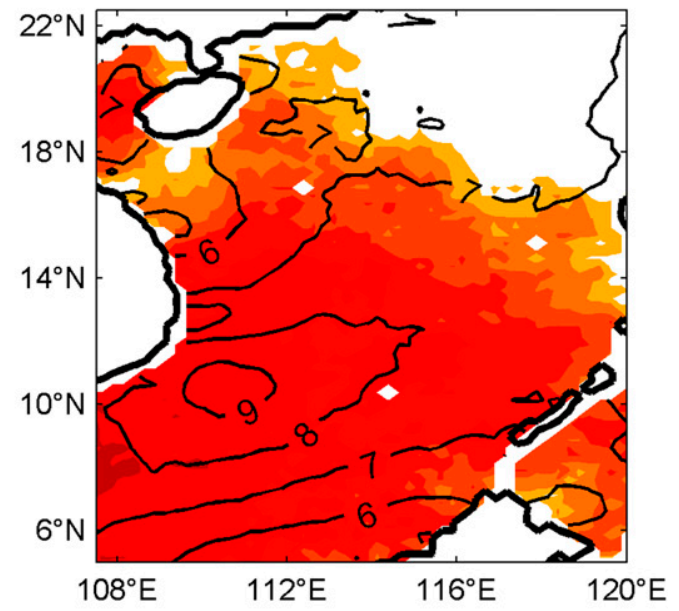

(d) Dec

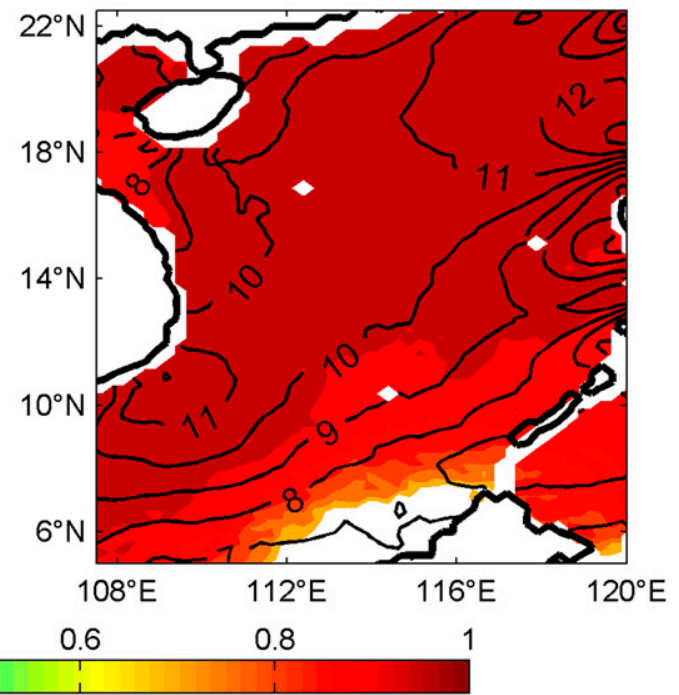

FIG. 4. Climatological wind directional steadiness (color shading; only values $\geq 0.7$ are plotted) and wind speed (contours; $\mathrm{m} \mathrm{s}^{-1}$ ) in (a) March, (b) July, (c) September, and (d) December.

magnitude of the wind speed and, in particular, the WDS are important in mesoscale coupling (e.g., Chelton et al. 2007; Castelao 2012; O'Neill 2012), but whether this is also true in the SCS is unknown.

Figure 4 shows the climatological wind speed and climatological WDS in March, July, September, and December. The WDS is defined as the magnitude of the vector-average wind speed divided by the scalar average of the wind speed magnitude computed from dailyaveraged QuikSCAT data in the representative months (Chelton et al. 2007):

$$
\mathrm{WDS}=\sum \mathbf{U} / \sum|\mathbf{U}|
$$

where $\mathbf{U}$ is the daily-averaged wind vector.
Therefore, if the wind direction at a location varies less during a particular month, then the magnitude of the monthly vector-averaged wind at this location will be very close to the monthly scalar average of winds at this location - that is, higher values of WDS correspond to steadier wind directions and lower values of WDS correspond to more variable wind directions. Figure 4 shows that, except for September, the winds over most of the SCS are fairly steady (WDS $>0.7$ ). Also, the wind speed is high $\left(>6 \mathrm{~m} \mathrm{~s}^{-1}\right)$ throughout the year. Although winds with WDS $>0.7$ are sufficiently steady for mesoscale coupling to develop (Chelton et al. 2007), there are still many regions where both the SST gradient and the WDS are high, with no significant coupling. For example, the wind is steady in July (Fig. 4b) and the 
MTG is strong (Fig. 2b) in most areas south of $16^{\circ} \mathrm{N}$, but significant coupling only appears in a small region off the east coast of Vietnam. The MTG is strong over the entire SCS in September (Fig. 2c) and the wind is steady in the southern SCS (Fig. 4c), but little significant coupling is found (Fig. 2c). A similar situation is seen in the region south of $10^{\circ} \mathrm{N}$ in December (Figs. $2 \mathrm{~d}$ and $4 \mathrm{~d}$ ).

These results suggest that neither the WDS nor the wind speed is the controlling factor in mesoscale coupling in the SCS, and we need to explain why the linkage between the WDS and the development of coupling in the SCS is not as significant as in other marginal seas. The marginal seas studied previously are mostly characterized by strong upwelling induced by strong and steady alongshore winds. This strong upwelling may also result in a strong SST gradient. Therefore, the wind intensity and steadiness and the SST gradient always vary in phase with each other and are significantly correlated with the intensity of coupling. By contrast, orographic effects and oceanic processes in the SCS also exert strong influences on the generation of the SST gradient, which, as a result, does not vary synchronously with the wind intensity and steadiness, explaining why the intensity of coupling in the SCS is not tightly correlated with either the WDS or the wind intensity as in other marginal seas. In addition, the wind speed and WDS in the SCS are sufficiently high for coupling to develop in most months of the year and therefore do not constrain the coupling. Coupling is only constrained when the wind is either too weak or insufficiently steady to support the development of coupling.

\section{b. Effects of wind speed steadiness}

The variation in winds includes the variation in both the wind direction and wind speed. As such, we investigate the effect of wind speed steadiness (WSS) on mesoscale coupling. The standard deviation (STD) of wind speed can be used as an index of WSS: a higher STD means that the wind speed is less stable, and vice versa. Because the variation in wind on a long time scale does not contribute to the magnitude of WSS in a certain month, we focus only on variations in wind speed with a period shorter than five weeks.

Figure 5 shows the climatological STD of the wind speed and the climatological SST of March, July, September, and December. In March, the variation in wind speed is very weak in the SCS, except for the coastal regions (especially the region to the west of Hainan Island, located in the northwest of the SCS), and the STD in most parts of the SCS is $<0.3 \mathrm{~m} \mathrm{~s}^{-1}$. By contrast, the wind speed in July and September is much more variable, and the STD exceeds $0.5 \mathrm{~m} \mathrm{~s}^{-1}$ in most regions. The distribution of the STD in December is different from the other three months: the STD is small to the north of $12^{\circ} \mathrm{N}$ and large to the south of $12^{\circ} \mathrm{N}$.

The MTG and WSS both need to be taken into account to interpret the spatial pattern of the intensity of coupling. The wind speed is stable in March (Fig. 5a), and therefore the influence of the SST on the wind field can be well established in regions where the MTG is strong. Almost all regions with a strong MTG show strong mesoscale coupling (Fig. 2a), except the region to the west of Hainan Island. The wind speed in this region is highly variable owing to orographic effects, and therefore the wind anomalies induced by the SST gradient are masked by the strong variation in the wind speed itself.

The MTG in July and September is sufficiently strong for mesoscale coupling, but the wind speed is unstable (Figs. 5b,c), and therefore the influence of the SST on the wind speed is masked by the energetic variability of the background wind field. Under such circumstances, weak correlations are expected between the SST and wind speed (Figs. 2b,c), and significant mesoscale coupling can only be detected where the MTG is very strong, such as in the region to the east of Vietnam (Fig. 5b). This theory can also explain the distribution of the intensity of coupling in December when the wind is relatively stable to the north of $10^{\circ} \mathrm{N}$. At this time, the change in wind speed induced by the SST accounts for a large part of the variation in wind speed, which is why strong mesoscale coupling is found in this region (Fig. 2d). By contrast, no significant coupling is detected in the southern SCS because the wind speed is unstable even though the MTG is higher than that in the northern SCS (Fig. 5d).

This analysis shows that WSS is important in understanding the relationship between the MTG and intensity of coupling in all seasons. Regions with a strong MTG but weak coupling coincide well with regions where the wind speed is unstable, whereas regions with a strong MTG and steady wind speed are all characterized by strong mesoscale coupling. Therefore, WSS, represented by the STD of wind speed, is an important factor in evaluating mesoscale coupling in the SCS, and is more effective than WDS. This is very different from the situation seen in other marginal seas.

What are the causes of wind instability in the SCS? The SCS is surrounded by many mountain ranges, and Xie et al. (2007) found that the orographic effects of these mountain ranges can significantly affect the atmosphere-ocean coupled system in the SCS. Chelton et al. (2007) found that the influence of coastal promontories on the wind field may extend several hundred kilometers from the capes. Therefore, the effects of orography and coastline geometry are probably the 
(a) Mar

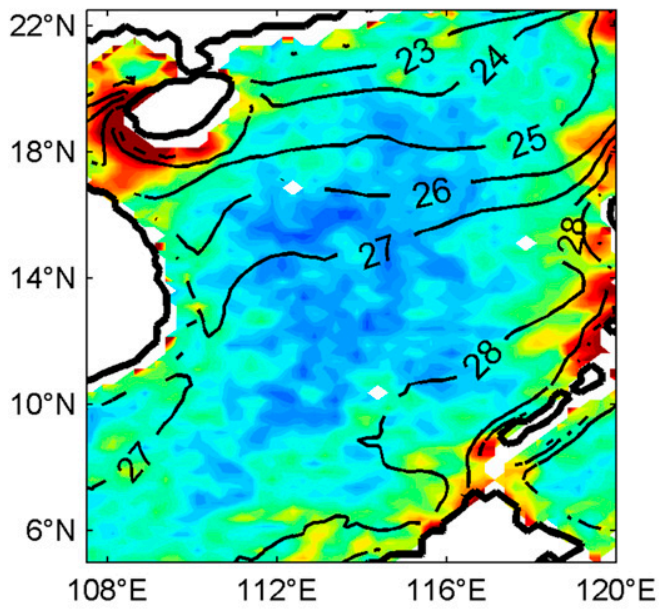

(c) Sep

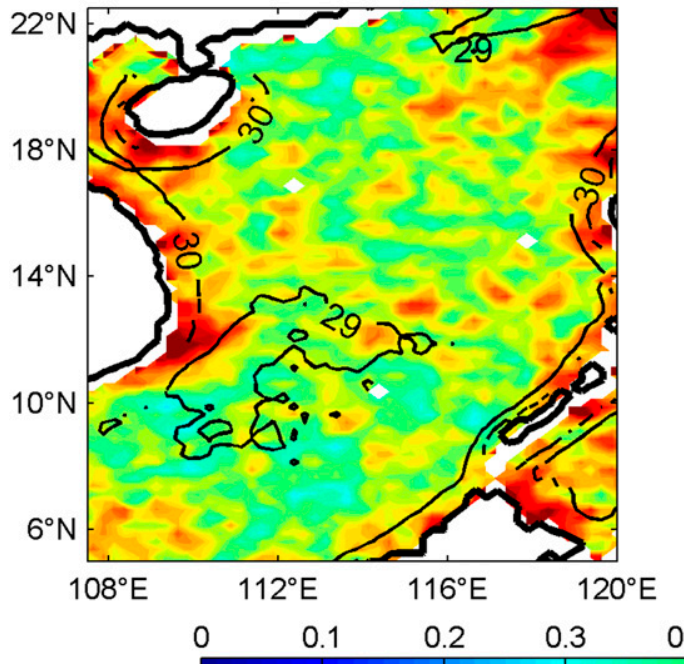

(b) Jul

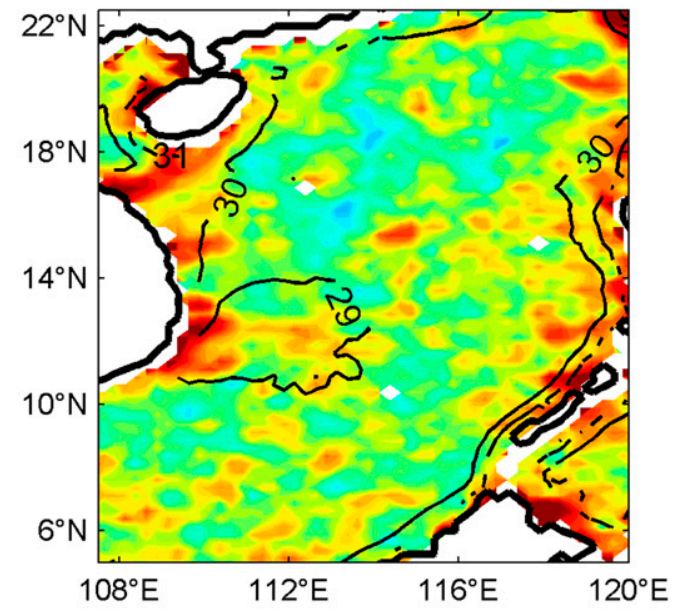

(d) Dec

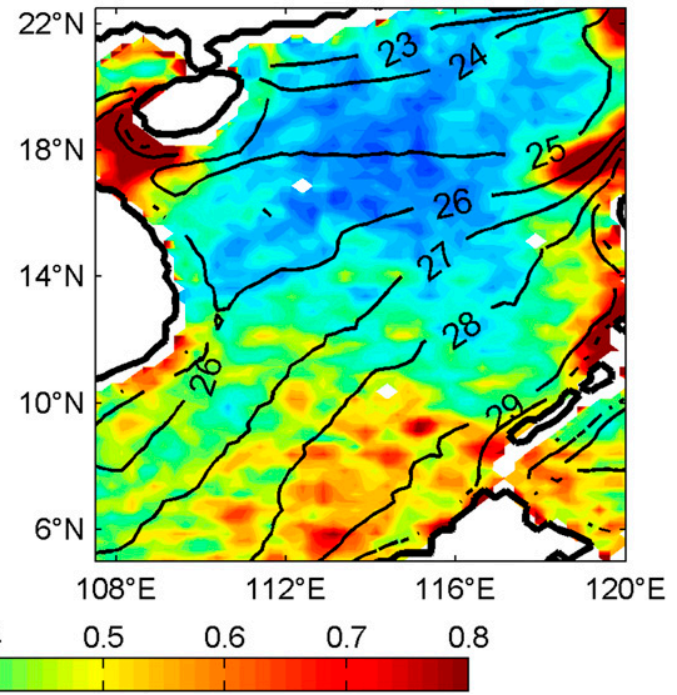

FIG. 5. Climatological wind speed steadiness (color shading; $\mathrm{m} \mathrm{s}^{-1}$ ) and climatological SST (contours; ${ }^{\circ} \mathrm{C}$ ) in (a) March, (b) July, (c) September, and (d) December.

most important causes of wind instability in coastal regions.

Another cause of wind instability is SST. In the current climate system, the threshold of SST for deep convection is usually around $26^{\circ}-27^{\circ} \mathrm{C}$, depending on the region and season. Over such warm oceans, a change in SST causes deep convective adjustment, which in turn excites a dynamic response of predominantly the first baroclinic mode structure with strong surface-wind signals (Xie 2004). According to Fig. 5, the STD of wind speed is fairly small when the SST is less than $28^{\circ} \mathrm{C}$, but increases dramatically where the SST is above this threshold.

The causes of wind speed instability can therefore be summarized as follows: When SST is less than $28^{\circ} \mathrm{C}$, the
STD of the wind speed in the SCS mainly depends on orographic effects. Therefore, the wind speed is steady in the central basin and unsteady in the coastal regions. When SST is greater than $28^{\circ} \mathrm{C}$, the wind speed becomes unsteady regardless of location.

The constraining effect of coastal orography on coupling has been reported in previous studies (e.g., Chelton et al. 2007; Desbiolles et al. 2014), but the effect of high SSTs has not been reported before in the literature. This is because the marginal seas studied before were not as warm as the SCS, or the warm region was insufficiently large to excite deep convection. By contrast, the SST in the SCS exceeds $28^{\circ} \mathrm{C}$ throughout the basin in summer and over most of the basin in the 
(a) Mar

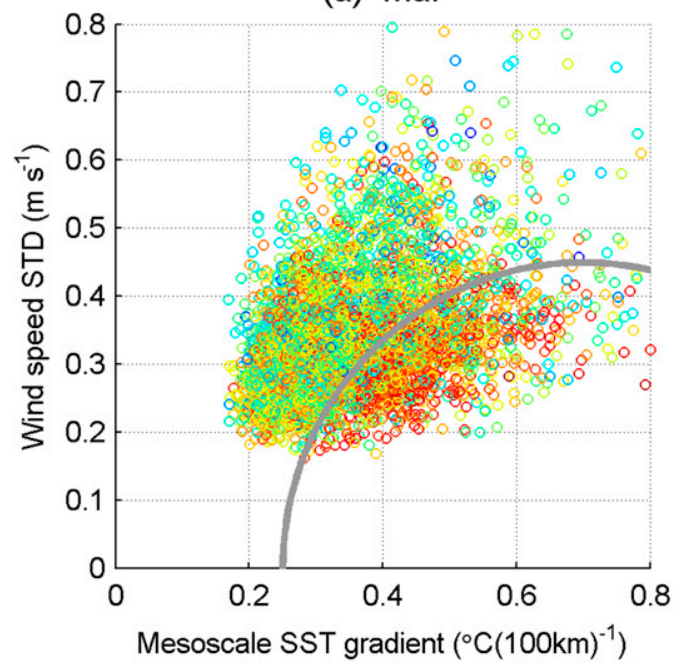

(c) Sep

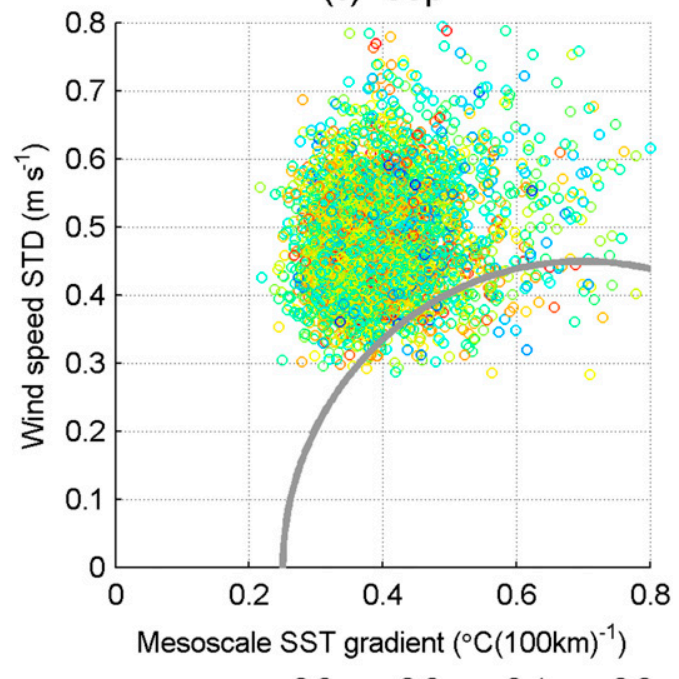

(b) Jul

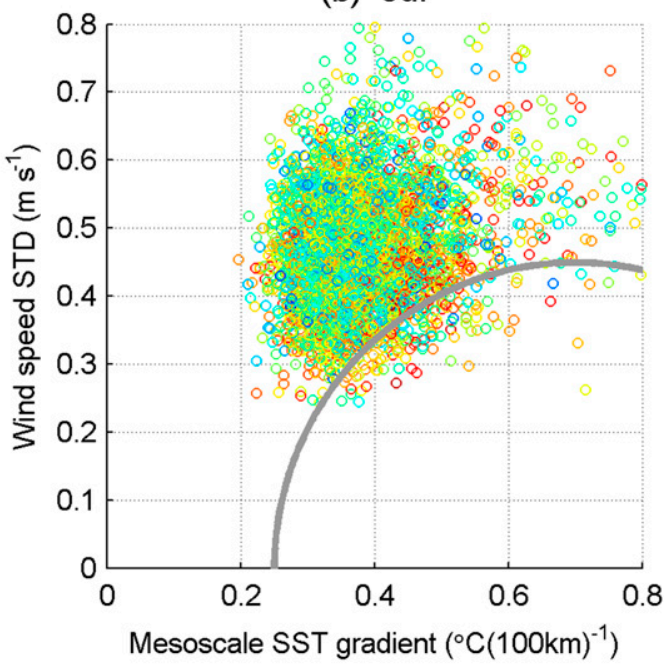

(d) Dec

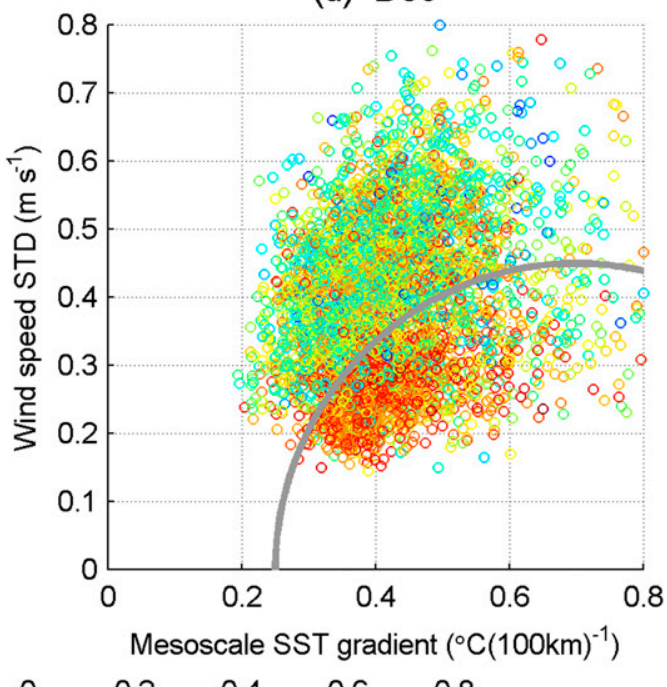

FIG. 6. Relationships among the mesoscale SST gradient $\left[x\right.$ axis; $\left.{ }^{\circ} \mathrm{C}(100 \mathrm{~km})^{-1}\right]$, wind speed STD $\left(y\right.$ axis; $\left.\mathrm{m} \mathrm{s}^{-1}\right)$, and intensity of coupling (color shading) in (a) March, (b) July, (c) September, and (d) December in the SCS. The gray curve is a part of the circle centered on $(0.7,0)$ with a radius of 0.45 .

fall, and therefore the wind speed instability induced by high SSTs becomes a major controlling factor in coupling.

\section{c. Joint effects of the MTG and WSS}

Coupling cannot occur over a moderate MTG if the wind speed is unstable; however, when the MTG is high enough, coupling can develop even if the wind speed is unstable. With this in mind, we investigate the joint effect of the MTG and WSS on the mesoscale intensity of coupling in different seasons.
In the late stage of the winter monsoon (represented by March; Fig. 6a), the STD of wind speed is mostly between 0.2 and $0.6 \mathrm{~m} \mathrm{~s}^{-1}$; and this is the season when the wind speed is steadiest. The coupling is significant in regions with both a steady wind speed and a strong MTG (the area under the gray curve in Fig. 6a). A strong MTG and high WSS combine to create favorable conditions for the development of coupling. When the MTG is less than $0.3^{\circ} \mathrm{C}(100 \mathrm{~km})^{-1}$, the intensity of coupling decreases dramatically, irrespective of the stability of the wind speed. 
(a) Jan

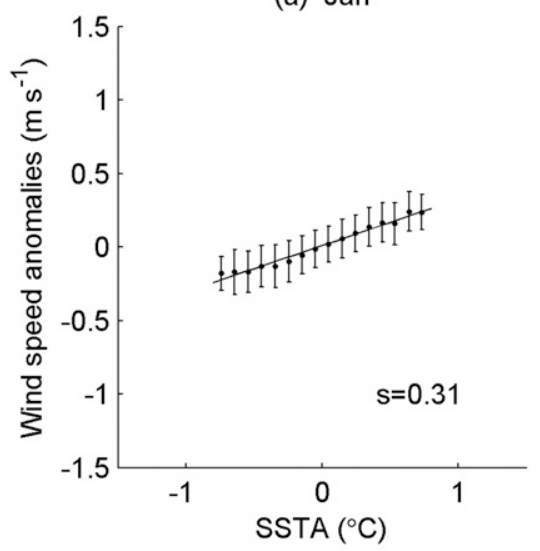

(d) Jun

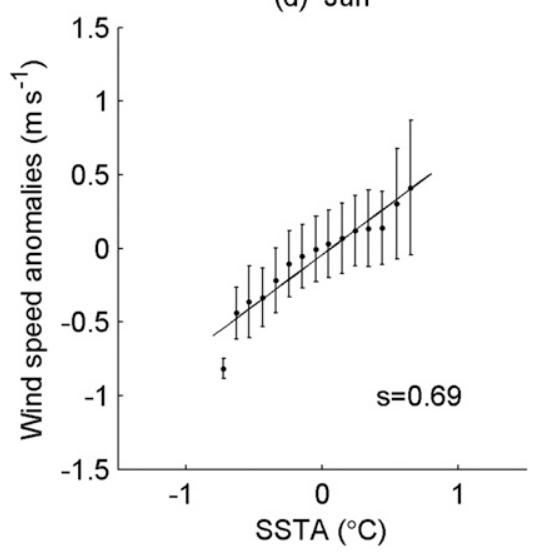

(b) Feb

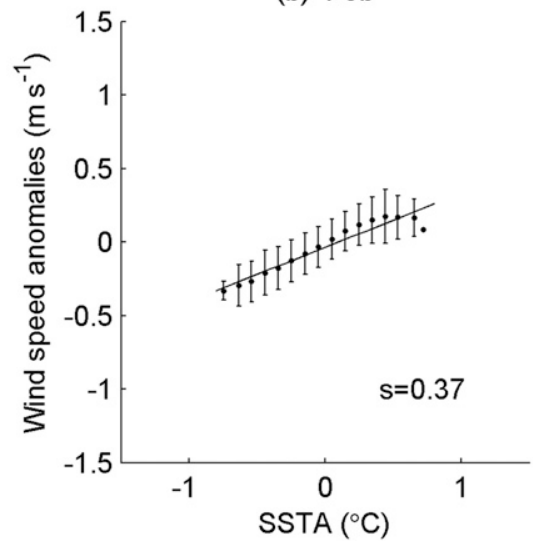

(e) Jul

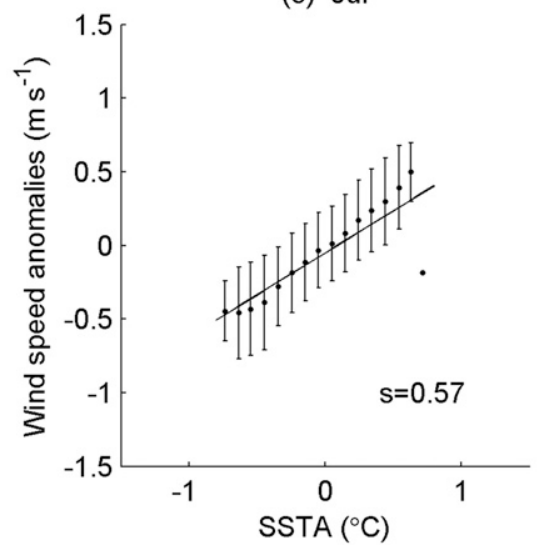

(c) Mar

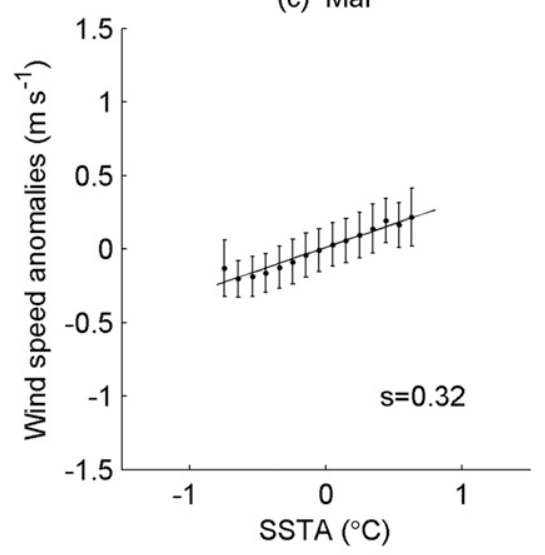

(f) Aug

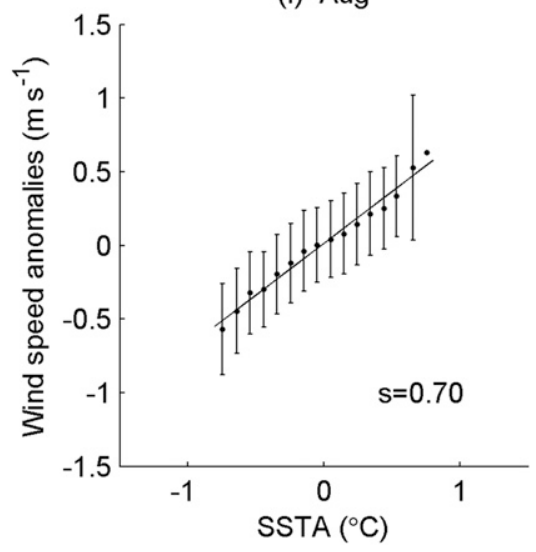

FIG. 7. Binned scatterplots of the variation in wind speed (mean and $\left.\pm 1 \mathrm{STD} ; \mathrm{m} \mathrm{s}^{-1}\right)$ vs SSTAs $\left({ }^{\circ} \mathrm{C}\right.$ ) over regions with strong coupling (black-outlined boxes in Fig. 1) in (a)-(c) winter and (d)-(f) summer. The dots and bars are the mean values and the \pm 1 STD of the wind speed variations, respectively; $s$ is the slope of the fitted straight line.

In the early stage of the winter monsoon (represented by December; Fig. 6d), the range of the STD is about $0.15-0.7 \mathrm{~m} \mathrm{~s}^{-1}$. The coupling is significant when the MTG is greater than $0.3^{\circ} \mathrm{C}(100 \mathrm{~km})^{-1}$ and the STD is less than $0.4 \mathrm{~m} \mathrm{~s}^{-1}$. This characteristic is similar to that in March. A higher MTG is necessary for significant coupling to occur when the STD increases or the wind speed is unsteady.

The STD in summer (represented by July; Fig. 6b) is much higher than that in winter and is greater than $0.3 \mathrm{~m} \mathrm{~s}^{-1}$ over the entire basin, suggesting that the wind is less steady in this season. As a result, the regions under the gray curve in Fig. $6 \mathrm{~b}$ are greatly reduced, leading to a weaker intensity of coupling. The situation in fall (represented by September; Fig. 6c) is similar to that in summer.

These results suggest that significant coupling always appears in regions where the MTG is strong and the wind speed is steady. However, in regions where the MTG is relatively weak, coupling only occurs when the wind speed is very steady. If the wind speed is less steady, a stronger MTG is required for coupling to develop. The gray curve in Fig. 6 can be used to judge whether mesoscale coupling in a region is significant.

To explore the characteristics of mesoscale coupling in different seasons, the relationship between variations in SSTAs and WSAs are qualified (Fig. 7). The statistics are computed over regions in which coupling is strongest in each season (black-outlined boxes in Fig. 1) The method used to calculate the coupling coefficient is similar to that used in previous work (e.g., Chelton et al. 2004; Ma et al. 2015). We compare winter (JanuaryMarch) and summer (June-August), which are the two typical monsoon seasons of the SCS. Figure 7 presents scatterplots of WSAs (mean and \pm 1 STD) versus binned SSTAs. The means of the WSAs can be fitted well with a straight line, suggesting that the variation in WSAs is linearly related to the variation in SSTAs, and therefore the slope of the fitted line can be used to represent the strength of coupling between the WSAs and SSTAs. 
Significance testing shows that all values of the slope are above the $99 \%$ confidence level.

Figure 7 shows two major differences in the coupling between winter and summer. First, the STD of the variation in WSAs (error bars in Fig. 7) is greater in summer than in winter. This is because the summer wind field is less stable, and therefore the response of the WSAs to the SSTAs has a wider range, leading to a greater STD of the variation in WSAs. Second, the coupling coefficient is larger in summer $\left(0.57-0.70 \mathrm{~m} \mathrm{~s}^{-1}{ }^{\circ} \mathrm{C}^{-1}\right)$ than in winter $\left(0.31-0.37 \mathrm{~m} \mathrm{~s}^{-1}{ }^{\circ} \mathrm{C}^{-1}\right)$. This is because the SST is relatively cold in winter, and therefore the vertical convection in the atmospheric boundary layer is weaker, resulting in a weaker response of the wind to anomalous SST forcing. The coupling coefficient in the SCS is comparable to that in major frontal zones and energetic eddy regions in open oceans, which is about $0.2-$ $0.6 \mathrm{~m} \mathrm{~s}^{-1}{ }^{\circ} \mathrm{C}^{-1}$ (Song et al. 2009; Chelton and Xie 2010; O’Neill 2012; Gaube et al. 2015).

\section{Conclusions}

Satellite measurements of wind speed by QuikSCAT and SST by the TMI product are analyzed to investigate the seasonal characteristics of mesoscale SST-wind speed coupling in the SCS and its underlying mechanisms.

The results show that the characteristics of mesoscale coupling possess pronounced seasonal variations. Both the correlation between SSTAs and WSAs and the location of regions with high correlation vary significantly with season. The correlation is highest in winter, second highest in summer, and weakest in the monsoon transitional periods. The region of high correlation is located in the central basin in the early stage of the winter monsoon, then moves gradually northward as the winter monsoon persists, and is ultimately located in the northern SCS during the late stage. The region of high correlation remains off the coast of southern Vietnam during the summer monsoon. Such complex variations in coupling are fundamentally different from those found in open oceans and other marginal seas. The SSTinduced perturbations of wind speed can induce modifications in wind stress curl, which feedback to the ocean through Ekman pumping. These processes can significantly affect the development, propagation and decay of mesoscale eddies (Park and Cornillon 2002; White and Annis 2003; Jin et al. 2009; Seo et al. 2016). The SCS is a region with numerous ocean eddies (e.g., Wang et al. 2003; Chen et al. 2011; Wang et al. 2015, 2018), and understanding the feedback effect of mesoscale coupling on eddies can be very helpful for studying eddy activities in regions where strong mesoscale coupling is detected.
There are two major controlling factors for mesoscale coupling in the SCS. The first is the MTG, which is a finding consistent with previous studies. Strong coupling always occurs in regions where the SST gradient is strong. However, a strong MTG is a necessary, but not sufficient, condition for the development of coupling. The second controlling factor is WSS. Although many studies have proved that WDS is important in the development of coupling, this is not true for the SCS. Our results suggest that WSS, represented by the STD of wind speed, is a better indicator with which to evaluate the constraining effect of the variability of wind on the development of mesoscale coupling in the SCS. This is the first time that WSS has been considered to be a controlling factor in the development of mesoscale coupling. Variations in WSS can explain the inconsistency between the spatial patterns of the MTG and the intensity of coupling in all seasons. Strong coupling can occur with a relatively low MTG when the wind speed STD is small. However, as the wind speed STD increases, the critical value of the MTG needed for strong coupling to develop increases correspondingly. The development of significant coupling depends on the relative contribution of these two factors.

This work has elucidated the main mechanisms underlying the seasonal variation of mesoscale SST-wind speed coupling in the SCS and will improve our understanding of mesoscale coupling in other marginal seas.

Acknowledgments. This work is supported by the National Natural Science Foundation of China (41676020, 41876030, 41576028, and 41605065), and the research fund from FIO-UM Joint Center of Marine Science and Technology.

\section{REFERENCES}

Bryan, F. O., R. Tomas, J. M. Dennis, D. B. Chelton, N. G. Loeb, and J. L. McClean, 2010: Frontal scale air-sea interaction in high-resolution coupled climate models. J. Climate, 23, 6277 6291, https://doi.org/10.1175/2010JCLI3665.1.

Castelao, R. M., 2012: Sea surface temperature and wind stress curl variability near a cape. J. Phys. Oceanogr., 42, 2073-2087, https://doi.org/10.1175/JPO-D-11-0224.1.

Chelton, D. B., and S. Xie, 2010: Coupled atmosphere-ocean interactions at ocean mesoscales. Oceanography, 23, 52-69, https://doi.org/10.5670/oceanog.2010.05.

_ , and Coauthors, 2001: Observations of coupling between surface wind stress and sea surface temperature in the eastern tropical Pacific. J. Climate, 14, 1479-1498, https://doi.org/ 10.1175/1520-0442(2001)014<1479:OOCBSW>2.0.CO;2.

, M. G. Schlax, M. H. Freilich, and R. F. Milliff, 2004: Satellite measurements reveal persistent small-scale features in ocean winds. Science, 303, 978-983, https://doi.org/10.1126/science. 1091901. 
,-- , tween sea surface temperature and wind stress in the California current system. J. Phys. Oceanogr., 37, 495-517, https:// doi.org/10.1175/JPO3025.1.

Chen, G., Y. Hou, and X. Chu, 2011: Mesoscale eddies in the South China Sea: Mean properties, spatiotemporal variability, and impact on thermohaline structure. J. Geophys. Res., 116, C06018, https://doi.org/10.1029/2010JC006716.

Chow, C. H., and Q. Liu, 2012: Eddy effects on sea surface temperature and sea surface wind in the continental slope region of the northern South China Sea. Geophys. Res. Lett., 39, L02601, https://doi.org/10.1029/2011GL050230.

Cleveland, W. S., and S. J. Devlin, 1988: Locally weighted regression: An approach to regression analysis by local fitting. J. Amer. Stat. Assoc., 83, 596-610, https://doi.org/10.1080/ 01621459.1988.10478639.

Cornillon, P., and K.-A. Park, 2001: Warm core ring velocities inferred from NSCAT. Geophys. Res. Lett., 28, 575-578, https:// doi.org/10.1029/2000GL011487.

Desbiolles, F., B. Blanke, A. Bentamy, and N. Grima, 2014: Origin of fine-scale wind stress curl structures in the Benguela and Canary upwelling systems. J. Geophys. Res. Oceans, 119, 7931-7948, https://doi.org/10.1002/2014JC010015.

Frenger, I., N. Gruber, R. Knutti, and M. Münnich, 2013: Imprint of Southern Ocean eddies on winds, clouds and rainfall. Nat. Geosci., 6, 608-612, https://doi.org/10.1038/ngeo1863.

Gaube, P., D. B. Chelton, R. M. Samelson, M. G. Schlax, and L. W. O'Neill, 2015: Satellite observations of mesoscale eddyinduced Ekman pumping. J. Phys. Oceanogr., 45, 104-132, https://doi.org/10.1175/JPO-D-14-0032.1.

Hashizume, H., S.-P. Xie, W. T. Liu, and K. Takeuchi, 2001: Local and remote atmospheric response to tropical instability waves: A global view from space. J. Geophys. Res., 106, 10 173-10 185, https://doi.org/10.1029/2000JD900684.

Hayes, S. P., M. J. McPhaden, and J. M. Wallace, 1989: The influence of sea-surface temperature on surface wind in the eastern equatorial Pacific: Weekly to monthly variability. J. Climate, $\mathbf{2}$, 1500-1506, https://doi.org/10.1175/1520-0442(1989)002<1500: TIOSST $>2.0 . \mathrm{CO} ; 2$.

Jin, X., C. Dong, J. Kurian, J. C. McWilliams, D. B. Chelton, and Z. Li, 2009: SST-wind interaction in coastal upwelling: Oceanic simulation with empirical coupling. J. Phys. Oceanogr., 39, 2957-2970, https://doi.org/10.1175/2009JPO4205.1.

Kelly, K. A., S. Dickinson, M. J. McPhaden, and G. C. Johnson, 2001: Ocean currents evident in satellite wind data. Geophys. Res. Lett., 28, 2469-2472, https://doi.org/10.1029/2000GL012610.

Lindzen, R. S., and S. Nigam, 1987: On the role of sea surface temperature gradients in forcing low-level winds and convergence in the tropics. J. Atmos. Sci., 44, 2418-2436, https:// doi.org/10.1175/1520-0469(1987)044<2418:OTROSS >2.0 $\mathrm{CO} ; 2$.

Ma, J., H. Xu, C. Dong, P. Lin, and Y. Liu, 2015: Atmospheric responses to oceanic eddies in the Kuroshio Extension region. J. Geophys. Res. Atmos., 120, 6313-6330, https://doi.org/ 10.1002/2014JD022930.

,-- , and — 2016: Seasonal variations in atmospheric responses to oceanic eddies in the Kuroshio Extension. Tellus, 68A, 31563, https://doi.org/10.3402/TELLUSA.V68.31563.

Ma, X., and Coauthors, 2016: Western boundary currents regulated by interaction between ocean eddies and the atmosphere. Nature, 535, 533-537, https://doi.org/10.1038/nature18640.

Nonaka, M., and S.-P. Xie, 2003: Covariations of sea surface temperature and wind over the Kuroshio and its extension:
Evidence for ocean-to-atmosphere feedback. J. Climate, 16, 1404-1413, https://doi.org/10.1175/1520-0442(2003)16<1404: COSSTA $>2.0 . \mathrm{CO} ; 2$.

Oerder, V., F. Colas, V. Echevin, S. Masson, C. Hourdin, S. Jullien, G. Madec, and F. Lemarié, 2016: Mesoscale SST-wind stress coupling in the Peru-Chile current system: Which mechanisms drive its seasonal variability? Climate Dyn., 47, 2309-2330, https://doi.org/10.1007/s00382-015-2965-7.

O'Neill, L. W., 2012: Wind speed and stability effects on coupling between surface wind stress and SST observed from buoys and satellite. J. Climate, 25, 1544-1569, https://doi.org/10.1175/ JCLI-D-11-00121.1.

, D. B. Chelton, and S. K. Esbensen, 2003: Observations of SST-induced perturbations of the wind stress field over the Southern Ocean on seasonal time scales. J. Climate, 16, 23402354, https://doi.org/10.1175/2780.1.

Park, K.-A., and P. C. Cornillon, 2002: Stability-induced modification of sea surface winds over Gulf Stream rings. Geophys. Res. Lett., 29, 2211, https://doi.org/10.1029/ 2001 GL014236.

Perlin, N., S. P. de Szoeke, D. B. Chelton, R. M. Samelson, E. D. Skyllingstad, and L. W. O'Neill, 2014: Modeling the atmospheric boundary layer wind response to mesoscale sea surface temperature perturbations. Mon. Wea. Rev., 142, 4284-4307, https://doi.org/10.1175/MWR-D-13-00332.1.

Qu, T., 2001: Role of ocean dynamics in determining the mean seasonal cycle of the South China Sea surface temperature. J. Geophys. Res., 106, 6943-6955, https://doi.org/10.1029/ $2000 \mathrm{JC} 000479$.

Ricciardulli, L., and F. Wentz, 2011: Reprocessed QuikSCAT (V04) wind vectors with Ku-2011 geophysical model function. Remote Sensing Systems Tech. Rep. 043011, 8 pp.

Seo, H., A. J. Miller, and J. R. Norris, 2016: Eddy-wind interaction in the California Current system: Dynamics and impacts. J. Phys. Oceanogr., 46, 439-459, https://doi.org/10.1175/JPOD-15-0086.1.

Small, R. J., and Coauthors, 2008: Air-sea interaction over ocean fronts and eddies. Dyn. Atmos. Oceans, 45, 274-319, https:// doi.org/10.1016/j.dynatmoce.2008.01.001.

Song, Q., D. B. Chelton, S. K. Esbensen, N. Thum, and L. W. O'Neill, 2009: Coupling between sea surface temperature and low-level winds in mesoscale numerical models. J. Climate, 22, 146-164, https://doi.org/10.1175/2008JCLI2488.1.

Sun, S., Y. Fang, B. Liu, and Tana, 2016: Coupling between SST and wind speed over mesoscale eddies in the South China Sea. Ocean Dyn., 66, 1467-1474, https://doi.org/10.1007/s10236016-0993-4.

Vecchi, G. A., S. P. Xie, and A. S. Fischer, 2004: Ocean-atmosphere covariability in the western Arabian Sea. J. Climate, 17, 1213-1224, https://doi.org/10.1175/1520-0442(2004)017<1213: OCITWA $>2.0 . \mathrm{CO} ; 2$

Wai, M. M.-K., and S. A. Stage, 1989: Dynamical analyses of marine atmospheric boundary layer structure near the Gulf Stream oceanic front. Quart. J. Roy. Meteor. Soc., 115, 29-44, https://doi.org/10.1002/qj.49711548503.

Wallace, J. M., T. P. Mitchell, and C. Deser, 1989: The influence of sea-surface temperature on surface wind in the eastern equatorial Pacific: Seasonal and interannual variability. J. Climate, 2, 1492-1499, https://doi.org/10.1175/1520-0442(1989) 002<1492:TIOSST>2.0.CO;2.

Wang, G., J. Su, and P. C. Chu, 2003: Mesoscale eddies in the South China Sea observed with altimeter data. Geophys. Res. Lett., 30, 2121, https://doi.org/10.1029/2003GL018532. 
- J. Li, C. Wang, and Y. Yan, 2012: Interactions among the winter monsoon, ocean eddy and ocean thermal front in the South China Sea. J. Geophys. Res., 117, C08002, https:// doi.org/10.1029/2012JC008007.

Wang, Q., L. Zeng, W. Zhou, Q. Xie, S. Cai, J. Yao, and D. Wang, 2015: Mesoscale eddies cases study at Xisha waters in the South China Sea in 2009/2010. J. Geophys. Res. Oceans, 120, 517-532, https://doi.org/10.1002/2014JC009814.

- - J J. Li, J. Chen, Y. He, J. Yao, D. Wang, and W. Zhou, 2018: Observed cross-shelf flow induced by mesoscale eddies in the northern South China Sea. J. Phys. Oceanogr., 48, 16091628, https://doi.org/10.1175/JPO-D-17-0180.1.

Wentz, F. J., C. Gentemann, D. Smith, and D. Chelton, 2000: Satellite measurements of sea surface temperature through clouds. Science, 288, 847-850, https://doi.org/10.1126/science.288.5467.847.

White, W. B., and J. L. Annis, 2003: Coupling of extratropical mesoscale eddies in the ocean to westerly winds in the atmospheric boundary layer. J. Phys. Oceanogr., 33, 1095-1107, https://doi.org/ 10.1175/1520-0485(2003)033<1095:COEMEI >2.0.CO;2.

Xie, S.-P., 2004: Satellite observations of cool ocean-atmosphere interaction. Bull. Amer. Meteor. Soc., 85, 195-208, https:// doi.org/10.1175/BAMS-85-2-195.

- W. T. Liu, Q. Liu, and M. Nonaka, 2001: Far-reaching effects of the Hawaiian Islands on the Pacific Ocean-atmosphere system. Science, 292, 2057-2060, https://doi.org/10.1126/ science.1059781.

-, Q. Xie, D. Wang, and W. T. Liu, 2003: Summer upwelling in the South China Sea and its role in regional climate variations. J. Geophys. Res., 108, 3261, https://doi.org/10.1029/2003 JC001867.

, C. H. Chang, Q. Xi, and D. Wang, 2007: Intraseasonal variability in the summer South China Sea: Wind jet, cold filament, and recirculations. J. Geophys. Res., 112, C10008, https:// doi.org/10.1029/2007JC004238. 